\title{
ÉTICA E IMAGEM: UM PERCURSO ${ }^{1}$
}

\author{
Ana Luiza Carvalho da Rocha \\ Cornelia Eckert
}

\section{Introdução}

Este artigo está estruturada em três partes. Num primeiro momento, apresentamos uma rápida revisão do que pode ser considerado um estado de arte da discussão sobre ética e imagem na pesquisa social brasileira, mais especificamente na Antropologia. Na segunda parte buscamos refletir sobre questões relacionadas a problemas advindos da experiência de pesquisadores com uso de imagem. Na terceira parte, tecemos reflexões em torno da ética e imagem.

\section{(1) Um rápido percurso sobre a discussão de ética e imagem na antropologia brasileira.}

Em 1993, durante o Seminário temático "O uso da imagem em ciências sociais, relevância e limites" organizado por Bela Feldman-Bianco, da UNICAMP, e Ana Maria Galano, da UFRJ, durante o $17^{\circ}$ Encontro Anual da ANPOCS (22 a 25 de outubro 1993), em Caxambu, MG, foi proposta a organização de uma rede de pesquisadores em ciências sociais interessados na reflexão sobre o uso da imagem como instrumento de pesquisa e método analítico.

Passados quatro anos, na $21^{\text {a }}$ Reunião da ANPOCS, em 1997, no mesmo local, a rede de pesquisadores que havia sido formalizada, em reunião, organizou o Comitê Imagem e Som da referida instituição, ficando um pesquisador por região responsável pelo levantamento das pesquisas com imagem em instituições, e por estados, cujos resultados foram publicados em livro organizado pelo Prof. Dr. Mauro Koury (UFPb), no ano seguinte (1998).

No entanto, no âmbito das reuniões da Associação Brasileira de Antropologia/ABA, a reflexão sobre a pesquisa com imagem já estava consolidado através da participação de pesquisadores em GTs e Mesas Redondas dirigidos ao tema

\footnotetext{
${ }^{1}$ Texto apresentado no MR Ética e o Uso da Imagem em Estudos Antropológicos Antropologia e Ética. Projeto ABA/FORD 2000/2001 Oficina n.1 Ética e pesquisa nos dias 14 e 15 de dezembro de 2000. IFCH, UFRGS, Porto Alegre/RS
} 
do uso da imagem na pesquisa em ciências Sociais Redondas. Este status se revela, sobretudo com a organização, no âmbito do referido evento, de Exposições Fotográficas e de Concursos de Melhor Filme Etnográfico, criado desde 1996, no $20^{\circ}$ Congresso da ABA, em Salvador.

O projeto Núcleo de Antropologia Visual do Programa de Pós Graduação em Antropologia Social/NAVISUAL, criado, desde 1989, junto ao Laboratório de Antropologia Social, acompanha o entusiasmo das instituições dirigidas ao ensino e a pesquisa em Antropologia em desenvolver pesquisa etnográfica a partir do uso de instrumentos audiovisual, e acoplada a uma reflexão epistemológica sobre o lugar da imagem na construção tanto do objeto quanto do método de investigação antropológica. No entanto, a questão específica sobre os direitos de uso de imagem, no que tange à relação entre a pesquisa etnográfica a partir de instrumentos audiovisuais e os preceitos contidos no código de ética da ABA estava ainda incipiente.

A preocupação entre os antropólogos crescia na mesma proporção em que crescia o interesse de pesquisadores e dos alunos em geral pelo uso de tais tecnologias audiovisuais no campo disciplinar da investigação antropológica. Um primeiro levantamento do uso de imagens em teses e dissertações defendidas no âmbito PPGAS foi feito pelo NAVISUAL, em $1997 .^{2}$

Em 1998, o NAVISUAL organizou um Forum Especial na $21^{\mathrm{a}}$ Reunião Brasileira de Antropologia, Vitória/ES, sobre Ética e Imagem, graças ao apoio da Presidente Mariza Corrêa, extremamente sensível à importância do tema nos tempos atuais. Vários pesquisadores e instituições apoiaram o ensejo como Vincent Carelli (CTI), Patrícia Monte-Mór e José Parente (Interior Produções), Clarice Peixoto (UERJ), Eliane Longo da Silva (FUNARTE), Carolina Paz (UFSC), Luiz Eduardo Jorge (IGPA), Mauro Koury (UFPa), Paula Morgado(USP), Etienne Samain (UNICAMP) entre tantos outros.

Por ocasião da reunião, ficou claro, entre os participantes, que o debate a propósito de questões éticas envolvendo o uso de instrumentos audiovisuais de contexto da pesquisa antropológica referia-se a emergência de uma reflexão mais acurada sobre os direitos de uso da imagem e os de propriedade intelectual. Além disto, pontuava-se,

\footnotetext{
${ }^{2} \mathrm{Na}$ ocasião eram bolsistas de aperfeiçoamento e iniciação científica no NAVISUAL os alunos Liliane Guterres, Adriane Rodolpho, Alfredo Barros, Leandra Mylius e Thaís Vieira, orientados por Cornelia Eckert e mais tarde também por Ana Luiza Carvalho da Rocha
} 
na ocasião, que discutir os direitos de imagem não é o mesmo que discutir direitos autorais, embora ambas as problemáticas, ética e jurídica, transcorrem entrelaçadas.

O debate com o público apontou, sobretudo, para dúvidas e questões em torno dos direitos autorais no que tange as inseguranças que nós, pesquisadores, temos em relação ao uso e reprodução da imagem e som. Citamos aqui algumas das dúvidas apontadas na ocasião do evento, das quais resultaram sugestões e reivindicações para ABA onde à instituição caberia (1) compor um comitê ou comissão de cientistas sociais associados para analisar com mais profundidade às questões relativas aos direitos de imagem e som relacionados à pesquisa social; (2) propor um modelo de documento "contrato" a ser utilizado por todos os pesquisadores que garantam os direitos da pesquisa e os direitos de privacidade e autoria dos informantes; (3) entrar em contato com o Centro dos Pesquisadores Cinema Brasileiro para conhecer sua experiência, e, finalmente (4) criar, na ANPOCS, mais um espaço de debates para dar continuidade a discussão sobre direitos de imagem e som, onde os professores Clarice Peixoto e Mauro Koury, dariam encaminhamento de um GT sobre o tema para a ANPOCS 98-99.

Destas reivindicações, a primeira encaminhada foi à organização do GT na ANPOCS sobre o tema Direitos de Imagem sendo que, para surpresa de todos a proposta não foi aceita pela Diretoria, significando uma frustração para a rede de pesquisadores interessada em avançar na discussão ética sobre a pesquisa com imagem e som.

Em Brasília, julho de 2000, durante a $22^{\mathrm{a}}$ Reunião da ABA, no momento em que assumia a nova Diretoria, a primeira reivindicação conseguiu finalmente ser apoiada convergindo com a proposta de sua nova gestão da ABA, sob a Presidência do Dr. Ruben George Oliven e a Vice-presidência da Dra. Guita Debert. Finalmente, sendo a comissão para o estudo de questões relativas aos direitos de imagem estruturada, durante a última reunião da ANPOCS, outubro 2000, em Petrópolis/RJ., ficando-se estabelecido que a Profa. Patrícia Monte-Mór coordenaria o grupo de pesquisadores em Antropologia Visual.

No Programa de Pós Graduação em Antropologia Social, nossa preocupação com a questão da ética associada ao uso de recursos audiovisuais na investigação antropológica tem se tornado cada vez mais crucial principalmente a partir da criação do site, na Internet, do Projeto Banco de Imagem e Efeitos Visuais/BIEV, coordenado por Cornelia Eckert e Ana Luiza Carvalho da Rocha, e desenvolvido no contexto do Projeto Integrado financiado pelo CNPq e FAPERGS, e apoio do PPGAS. 
Com atuação tanto no NAVISUAL quanto no BIEV, as pesquisadoras tem buscado ampliar o debate em torno das questões éticas que conformam, para o antropólogo, a pesquisa etnográfica a partir dos usos da imagem técnica (fotográfica ou videográfica), seja junto aos seus bolsistas de iniciação científica, seja no curso de graduação na disciplina Seminário Livre Antropologia Visual, seja ainda no curso de Pós Graduação, na disciplina Antropologia Visual e Imagem.

(2) Use luz baixa sob neblina ou.... a atenção redobrada quando se trata de pesquisa com imagem e som

Inúmeros problemas enfrentados por antropólogos, nos últimos anos, podem exemplificar sobre os diferentes percalços a serem enfrentados pelo pesquisador que utiliza-se de instrumentos audiovisuais como técnicas de registo documental, no seu trabalho de campo, ou valhe-se da imagem para a construção de narrativas etnográficas cujos lugares de enunciação ultrapassam a sua comunidade lingüística de origem, ou seja, a academia.

José Parente enfrentou, há alguns anos, problema com um processo judicial por usar, no seu premiado documentário Rio de Memórias, a foto de uma mulher que aparece de costas na praia, e que, entretanto, por ter sido comprada em uma agência que a vendera ao pesquisador, isentou-o dos compromissos legais. Da mesma forma Dominique Gallois enfrentou problemas similares, mais em grau mais complexo, com sua pesquisa junto ao Waiapi, através da atuação e proposta de pesquisa compartilhada de imagem da CTI de São Paulo.

Os próprios pesquisadores do NAVISUAL, em 1997, ao expormos, no Museu da Dúvida, fotos da pesquisa de uma aluna sobre um culto afro, em Porto Alegre, fomos procurados pelo pai de santo que havia consentido no uso das imagens, na época, na dissertação, e que, agora, em exposição no espaço público, mudara radicalmente de opinião, solicitando a retirada de uma das fotos que fazia parte da coleção apresentada ao público. Imediatamente, atendendo a solicitação, retiramos as fotos que havia gerado tal polêmica e, logo após, iniciamos uma discussão sobre o problema dos limites jurídicos do consentimento oral fornecidos por pessoas entrevistadas, na ocasião da pesquisa de campo e elaboração de dissertação ou tese, e um consentimento por escrito, no momento da sua divulgação para o espaço extra-acadêmico. A partir daí a necessidade de um documento assinado, testemunhando o consentimento do uso da 
imagem e som para fins de pesquisa (jamais comerciais), tornando-se uma constante na prática de campo.

Exemplos como estes acima mencionados conduzem a constatação da importância de se fazer avançar uma discussão sistemática da utilização dos instrumentos audiovisuais na pesquisa de campo, implicando aí uma reflexão crítica do desempenho do pesquisador na relação com os sujeitos pesquisados.

No entanto, a reflexão crítica por si só não garante necessariamente que os conflitos entre o pesquisador e seu objeto, por sua vez ele próprio um sujeito social, sejam eliminados ou dirimidos uma vez que a própria interação entre ambos possui uma inscrição histórica. Vejamos esta manchete CANADA PROÍBE FOTO DE PESSOAS COMUNS, publicada na Folha de São Paulo, Folha Mundo, Primeiro Caderno, pagina 9, sexta feira, 10 de abril de 1998, que informa: “A justiça Canadense decidiu que publicar a foto de uma pessoa que esteja em local publico sem a autorização dela constitui invasão de privacidade. A decisão, tomada pela Suprema Corte do país, encerrou o caso da menina Pascale-Claude Aubry, que processava o fotografo Gilbert Duclos, da "ViceVersa".

Segundo a matéria publicada no jornal a revista havia publicado uma foto de Aubry na porta de sua escola, em Montreal, como ilustração de material sobre a vida cotidiana nas cidades canadenses. No entanto, segundo a justiça, "a expressão artística do fotógrafo, que teria servido para ilustrar a vida urbana contemporânea, não justifica a violação do direito a privacidade". A Suprema Corte canadense sustenta que os fotógrafos podem retratar apenas personalidades publicas, sendo que fotos de pessoas comuns, sem autorização delas, estão proibidas, conforme a noticia publicada na Folha Mundo. São Paulo, 10 de abril de 1998, p.09.

No Brasil, a pesquisa com imagem junto a grupos indígenas, no que diz respeito aos direitos autorais, está regulamentada e, aparentemente, transcorrendo de forma mais clara e objetiva do que a pesquisa no meio urbano. Sem dúvida, a crescente disseminação/divulgação de imagem dos índios brasileiros por fotógrafos e televisões estrangeiras, a FUNAI e algumas tribos indígenas controlam o retorno dos direitos autorais de imagem, e segundo depoimento do colega Manuel Ferreira Filho, na pesquisa do IGPA junto aos índios Carajás, na Ilha do Bananal/Brasil Central, esta situação nas áreas indígenas está sob controle já há algum tempo.

Se tomarmos o Código de Ética da Associação Brasileira de Antropologia, sobretudo no que se refere ao respeito ao grupo pesquisado, a aceitação por parte da 
comunidade da convivência com o "mal necessário", o antropólogo, pode-se sugerir que o cuidado com a aceitação formal da entrada em campo deve ser redobrado quanto se trata de pesquisa com imagem.

John Collier Jr em seu artigo "Antropologia visual: a fotografia como método de pesquisa" (Ed. USP, 1973, p. 61), nos atenta para o fato de que a "fotografia pode nos fornecer um ponto de apoio numa comunidade", porém, do mesmo modo, rápida e totalmente, os recursos audiovisuais podem tornar frágeis nossos laços com o outro se fizermos a intrusão indevida no seu cotidiano de equipamentos de gravação. Para o autor, deve-se ter claro que, quando começamos "a fotografar os trabalhos internos de estrutura social (oposta à sua forma institucionalizada externa), deixamos o domínio público e penetramos nos limites do comportamento e da crença mais privados."

Segundo Collier (1973), "podemos fotografar livremente nas áreas externas de agrupamentos públicos e de tecnologias básicas, porém, quanto mais nos aprofundamos, mais o terreno se torna traiçoeiro, e deveríamos aceitar o fato de que pode haver lugares sacros ocultos, os quais nunca seremos capazes de observar com a câmara. Temos estas circunstâncias em nossa própria cultura, onde fotografar pode ser completamente inaceitável, extremamente perigoso ou literalmente impossível".

A advertência a ser feita, aqui no caso, é que na maioria das culturas há objetos, lugares e pessoas que não devem ser vistos pela câmera, trata-se de se compreender "quando uma situação deixa de ser pública", sendo que isto não ocorre ao acaso, mas dentro de "uma circunstância culturalmente determinada" (1973:63). Aliás, segundo nos alerta Collier, tirar a foto à distância ou próxima, pode mudar muito de uma cultura para outra, ou seja, "cada cultura estabelece sua distância".

Para compreender a questão ética da "invasão" que o uso de recursos audiovisuais por antropólogos pode desencadear em campo, podemos nos referir ao estudo de Edward T. Hall, The Hidden Dimension (1966:63), onde o autor aponta para as distinções culturais do Ego quanto à utilização do espaço. As observações de E. Hall sobre o relativismo cultural que preside as formas de organização das interações humanas no espaço e no tempo embora não sendo estranhas aos próprios antropólogos, quando aplicadas ao uso de recursos audiovisuais em sua própria conduta em campo, estranhamente são esquecidas.

No entanto, é justamente quando nós construímos/fabricamos a imagem do Outro através de tecnologias audiovisuais é que aqui a "autoridade etnográfica" deveria ser discutida com mais rigor. Os equipamentos audiovisuais para registro etnográfico 
não são apenas máquinas destituídas de qualquer valor simbólico, ao contrário, sua utilização pelo pesquisador situa o registro "documental" visual, em Antropologia, no contexto de uma cultura visual de cunho "museológica" que tem sido o sustentáculo tanto da produção quanto do consumo culturais da imagem do Outro no mundo contemporâneo.

Aludindo a um isomorfismo do funcionamento do aparelho sensório, perceptivo e motor humano, os equipamentos audiovisuais pretendem simular os estados físicos e mentais do próprio antropólogo. Eles estão ali não só ocupando o lugar dos olhos, dos ouvidos e do próprio corpo do próprio investigador na interação com o Outro, mas, principalmente estão ali registrando tudo aquilo que para o Outro antes era privado e que, a partir daí, adquire o estatuto de uma representação na esfera pública.

Se para John Collier Jr. (1973), “em geral, as anotações fotográficas devem ser tratadas da mesma maneira que as outras anotações de pesquisa de campo. Material obtido em segredo deve ser mantido em segredo, porque é um ato da maior confiança para uma família deixá-lo registrar a vida particular dela."

No PPGAS, grande cuidado tem sido tomado a respeito quanto ao uso de imagens nas dissertações de mestrado, teses de doutorado tanto quanto na produção audiovisual. A pesquisadora Claudia Turra Magni, não tem autorizado a exibição na televisão do vídeo produzido vinculado a sua dissertação de mestrado "Nômades urbanos", uma vez que vários dos personagens do documentário enfrentam, hoje, problemas e conflitos com a polícia ou foram mortos dado suas condições de vida.

O maior problema que enfrentamos tem sido especificamente ao longo do processo de formação na graduação e na pós-graduação, através da disciplina Antropologia visual e imagem. Sobretudo, no curso de graduação, onde jovens acostumados ao consumo banal da imagem técnica nas suas vidas cotidianas (via industria de entretenimento) tendem a se empolgar frente a possibilidade de reproduzir a indústria do espetáculo no uso dos instrumentos audiovisuais como técnica de pesquisa nas ciências sociais.

O esforço em enfocar a questão ética sobre o uso da imagem nas ciências sociais é, pois, uma tarefa pedagógica fundamental que acompanha o tema das aprendizagens em torno do uso de recursos audiovisuais na pesquisa antropológica, uma vez que os alunos têm que ser orientados, no sentido de refletirem sobre comportamento ético que irá orientar, posteriormente, a imagem do outro. 
Além disto, trata-se também de conduzir a turma de alunos a uma reflexão mais atenta sobre os perigos da estética do espetáculo na construção da imagem do Outro e que pode transformar o olhar antropológico sobre a cultura do Outro em um olhar obsceno, um olhar iconoclasta, preocupado em desvendar, eternamente, tudo o que está fora de cena.

O tema da ética diz respeito aqui a aprendizagem de que, na cultura visual do séc. XX, a imagem técnica ainda é portadora da ilusão de, através da grafia da luz, o pesquisador atingiria toda a "assinatura" e "nominação" das coisas pela cultura e, por consequiência, captaria a designação extrínseca da cultura e de suas marcas no Outro.”

O aluno, impregnado do fascínio pela civilização da imagem, tende a esquecer a "grafia da luz" que preside a experiência noética da interpretação da cultura do Outro, ou seja, as condições sob as quais o próprio pensamento do antropólogo constrói, reproduz e disponibiliza para o mundo acadêmico, ou não, essa imagem. Para sair do impasse o aluno, então, passa a considerar a construção da imagem do Outro apenas um reflexo das condições nas quais o seu pensamento processa uma reflexão sobre as diferenças culturais, isto é, uma projeção da sua própria luz interior.

A aprendizagem da ética no campo da pesquisa antropológica com imagens reside na aprendizagem de que a produção/reprodução/disseminação de imagens do Outro engaja toda uma reflexão inquietante em torno da consciência de si e do outro dão longo e após o trabalho de campo. Em Antropologia visual não se trata de ler o destino dos homens na face das coisas, o que significaria o tratamento da identidade de uma cultura a partir dos objetos da representação empírica que captamos com nossos equipamentos audiovisuais, mas de compreender que a investigação antropológica através de tais tecnologias exige uma conversão do antropólogo nas condições reflexiva e reversível nas quais se gesta seu próprio pensamento.

(3) O consumo cultural do exótico e do bizarro, o uso da imagem na articulação colonial do homem

Povos ditos "exóticos" reclamam hoje a devolução de objetos e imagens apropriadas no processo de colonização por Europeus, cimentada na política de musealização do processo civilizatório. Este fenômeno nos mostra que a imagem técnica (fotográfica, fílmica, videográfica, digital, eletrônica, etc.), no plano da cultura visual do mundo urbano-industrial, moderno-contemporâneo, constrói não só narrativas 
sobre nós mesmos, mas sobre nós mesmos face ao mundo do Outro, num processo de construção de um patrimônio do mundo.

Os ganhos democráticos e humanistas neste final de século apontam, portanto, para uma pesquisa compartilhada, reflexiva, hermenêutica, interpretativa, dialógica, crítica, etc. Os rótulos se sucedem uns mais eficazes que outros.

Entretanto, o que importa reter é que, meio ao tema da discriminação/exclusão social e cultural da diferença a responsabilidade frente às imagens com as quais veiculamos/disseminamos/disponibilizamos a idéia humanidade, tornou-se hoje um projeto de investigação também de nossa disciplina, a Antropologia.

O importante, hoje, é, cada vez mais, manter o espaço aberto para uma reflexão sobre o desempenho epistemológico da própria Antropologia, como a realização deste evento o comprova. Uma atenção redobrada para o tema do compromisso ético da Antropologia.

Sob este ângulo, concordamos todos que vídeos etnográficos e a produção fotográfica de pesquisas etnográficas ganharam, nesta década, uma relevância significativa na academia antropológica. Refletindo sobre esta interface entre antropologia/etnografia e a produção audiovisual, David Mac Dougall (1992:75) se interroga sobre a possibilidade da produção de uma etnografia visual conceitual, isto é, que opere com idéias: documentários "de idéias" que contemplem "níveis de significações culturais através de diferentes aspectos da vida cotidiana”.

Com MacDougall, tecemos aqui, como exemplo, alguns comentários a respeito do processo de produção e realização de vídeos etnográficos que têm como tema propulsor o tratamento documental da memória coletiva no mundo urbano contemporâneo. Neste final de século, parece-nos pertinente problematizar a construção de documentários etnográficos que tem o conceito de memória como princípio narrativo, tecendo e entrecruzando discursos e imagens que confrontam os esquecimentos e as lembranças nos permitindo de alguma forma refletir sobre as imagens e configurações do mundo que estas acabam por promover ou desconstruir.

Neste ponto, os exercícios de narrativas fotográficas e filmicas produzidos, por antropólogos, em suas etnografias das representações e ações humanas, tem freqüentemente traduzido, em imagens, a interpretação da interpretação da vida vivida por povos e civilizações, ao lhe permitir o registro da dinâmica de uma memória coletiva. 
Sem dúvida, o século $\mathrm{XX}$ foi o século da memória. As ciências, a literatura, as artes, enfim, foram múltiplas as formas de tradução da memória do mundo. O contexto das transformações na organização das formas de vida social nos grandes centros urbano, o industrialismo, o surgimento de uma cultura do espetáculo e as ilusões associadas ao progresso da técnica como parte constituinte do agenciamento humano do tempo $^{3}$, corresponderiam e aos experimentos com a técnica da fotografia e à invenção do cinematógrafo, em fins do séc. XIX, até finalizar, nos dias de hoje, com o computador e as redes digitais e eletrônicas. ${ }^{4}$

Em geral, poder-se-ia argumentar que a produção de filmes etnográficos, em Antropologia, por sua forma de registro documental, esta, portanto, intrinsecamente vinculado ao tema do tratamento conceitual da idéia de duração, ao revelar a presença, nas tecnologias audiovisuais, de uma métrica singular produzida pela inteligência humana próxima aos jogos da memória, isto é, uma rítmica capaz de fazer operar a ilusão de uma seriação dos acontecimentos segundo uma ordem de sucessão, sob o pano de fundo da descontinuidade de estruturas espaço-temporais. ${ }^{5}$

A técnica de registro documental de fatos, eventos, acontecimentos sociais por meios tecnológicos cada vez mais sofisticados (fotografia, cinema, vídeo, as novas tecnologias da informática) tem revelado ao homem moderno a sua capacidade de desvendar mundos sensíveis que não eram antes percebidos: a poesia dos atos e falas humanas ordinárias e cotidianas, por exemplo, o conhecimento e a precisão dos fatos observados pela ciência; a composição dos movimentos que encerram as ações de homens e animais em seus detalhes estruturais, o armazenamento de informações através de programas de computadores, etc.

Impossível não se perceber que as invenções tecnológicas de registro audiovisual, na condição de suportes materiais da memória, são herdeiras legítima do ideário da Modernidade que conforma um olhar humano sobre o mundo, e cuja finalidade permanece sendo, precisamente, observar e dissecar a realidade para melhor descrevê-

\footnotetext{
${ }^{3}$ Referimo-nos aqui a inúmeros destes aspectos tais como a eletricidade como fenômeno que orienta o controle dos ritmos naturais do tempo nos grandes centros industriais, a formação de grandes impérios coloniais e o encurtamento das distancias que separavam o homem ocidental de povos e civilizações, antes longínquos; o crescimento de consumo cultural do exótico e do bizarro; o desenvolvimento da industria do turismo e sua sede voraz de novas paisagens humanas e naturais, etc.

${ }^{4}$ Cf. SUBIRATS, E. A Cultura como espetáculo,. São Paulo, Nobel, 1989.

${ }^{5}$ O uso da metáfora da música por PIAGET, 1978, e BACHELARD, 1989., é revelador pois permite a ambos os autores traçar um quadro aproximativo da forma como a matéria se faz presente na regularidade da frequiência de suas ondulações apud Eckert e Rocha 199.
} 
la, escrutiná-la, dominá-la e, correlato a este processo, armazenar suas informações, ${ }^{6}$ todas elas correlatas de novas possibilidades de museologização do mundo

Isto porque, se, por um lado, este processo atende ao consumo de informações e dados sobre o Outro, nos quadros de uma celebração do próprio homem ocidental, europeu, branco e civilizado, - mantendo algum parentesco com os antigos cabinets de curiosité -, por outro, ele traduz uma demanda arquivística cada vez mais presente à formação da cultura objetiva no Ocidente moderno, progressivamente voltada ao fenômeno do registro de coleções documentais, com forte inspiração na idéia da "consciência histórica" do homem da civilização a partir da construção das diferenças culturais. $^{7}$

Em especial, para nós, trata-se de refletir eticamente a respeito dos perigos da dimensão formal da representação com que genericamente a cultura visual do mundo contemporâneo criou e produziu imagens estereotipadas e discriminatórias do Outro (seja qual for seu status: analógico, digital, eletrônico), imagens que muitas vezes criam a alteridade fixada no signo da diferença cultural/histórica e racial de um discurso colonialista e que podem vir a ser, logo após, pela via da globalização cultural, disponibilizadas, acessadas e apropriadas nos quadros do consumo do exótico.

Convém que seja apontado, no âmbito de uma reflexão sobre ética e imagem, que muitas vezes o uso das tecnologias audiovisuais na pesquisa em Antropologia, como já afirmamos aqui, atende a demanda de standartização de uma cultura do consumo, sem questionamento em torno do modo de representação da alteridade nos limites do discurso representacional do Ocidente.

Assim, sem indagar-se a respeito da necessária politização dos meios de representação (como aparato de poder de um discurso colonial), a Antropologia visual pode sempre recair na idéia segundo Manovich de que "the subjects have to be standardized, and the means by wich they are standardized need to be standardized as well", isto é, 'the private and individual is translated into public and becomes regulated". 8

\footnotetext{
${ }^{6}$ A idéia, por exemplo, do fusil fotográfico, disparando a intervalos regulares de Demeny e do uso de inúmeras câmeras para capturar o fenômeno em suas diferentes posições (Marey), são um exemplo do que vimos afirmando, cf. A MACHADO, Pré-cinemas \& Pós-Cinemas, São Paulo, Papirus, 1997, e E. BARNOW, El documental, historia y estilo, Barcelona, GEDISA, 1996.

7 Trata-se aqui de se pontuar criticamente os limites possíveis das novas tecnologias na produção de textos etnográficos no que diz respeito aos temas da produção/criação/apropriação de imagens do Outro e do documental, tendo como foco de atenção seus vínculos com as transformações sofridas pelas noções de testemunho/autenticidade/verdade no cômputo do mundo urbano-contemporâneo.

${ }^{8}$ Cf. L. MANOVICH, From the externalization..., http://www.manovich.net/TEXT/externalization.html
} 
O tema, Ética e Imagem, permite, portanto, que uma reflexão fundamental sobre a especificidade da experiência de uso de recursos audiovisuais como instrumento metodológica na produção da pesquisa antropológica tanto quanto possibilidade de narrativa etnográfica no corpo dos espaços convencionais de pesquisa em ciências sociais, isto é, no sentido de pontuar o lugar histórico complexo e frágil que nele ocupa o antropólogo quando se trata dele situar o lugar da sua prática profissional nas formas de representação visual das especificidades históricas e diversidade culturais que conformam a humanidade.

Ao se incorporar, neste paper, uma reflexão mais criteriosa a respeito dos constrangimentos históricos e sociais aplicados ao campo das tecnologias audiovisuais e, no seu interior, o estudo das relações problemáticas entre imagem, subjetividade, verdade e representações, parafraseando P. Rabinow ${ }^{9}$, trata-se, aqui, de ver que tais tecnologias reafirmam a idéia de que, para o caso das modernas sociedades contemporâneas, cada vez mais vivemos in-between, isto é, "no meio" da reificação de identidades locais ou de construção de identidades universais.

Por tudo o que vimos comentando é que consideramos o uso da imagem na pesquisa antropológica, um espaço privilegiado de reflexão em torno visibilidade representacional das formas de alteridade cultural, e isto porque é justamente através dela que obtemos, como num jogo de espelhos, a chave de interpretação dos tempos e espaços sociais que conformam, ainda hoje, a autoridade do discurso colonial no coração da sua própria prática de investigação.

\section{REFERÊNCIAS}

BARNOW, El documental, historia y estilo. Barcelona, GEDISA, 1998

COLLIER J. J.. Avaliação e interpretação do inventario cultural In: Antropologia visual: a fotografia como método de pesquisa. Coleção antropologia e sociologia. São Paulo 1973. EPU EUSP.

ECKERT, C e ROCHA, A. L. A interioridade da experiência temporal do antropólogo como condição da produção etnográfica. Revista de Antropologia. Dep. Antropologia. FFLCH, USP. V 41, n2, SP, 1998, p. 107 a 136.

HALL, Edward T. The Hidden Dimension Anchor Books, 1966.

MAC DOUGALL, D. "Films de Mémoire". In: PIAULT, Colette (Coordination). Journal des Anthropologues, Anthropologie Visuelle, número Special 47-48, Printemps 1992 p. 75

MACHADO, A. Pré-cinemas \& Pós-Cinemas, São Paulo, Papirus, 1997.

BARNOW, El documental, historia y estilo, Barcelona, GEDISA, 1996.

\footnotetext{
${ }^{9}$ Cf. P RABINOW, idem, op. cit, p. 100 .
} 
MANOVICH, Lev. From the Externalization of the Psyche to the Implantation of Technology . http://www.manovich.net/TEXT/externalization.html acesso março 2000.

RABINOW, Paul. Antropologia da Razão. RJ, Dumará, 1999.

SUBIRATS, E. A Cultura como espetáculo,. São Paulo, Nobel, 1989 